\title{
UreC and ZapA virulence genes amplification in clinical specimen of Proteus mirabilis in Bayelsa state, Nigeria
}

\begin{abstract}
Background and objective: Proteus mirabilis is part of the Enterobacteriaceae family, Gram negative bacterium which typically lives in the human gut, which means when it causes illness it can be a serious bloodstream infection, urinary tract infection or disseminated infection. UreC and ZapA virulent genes constitute the major pathogenicity of this organism as well as its resistance to antibiotics. This study was carried out to detect the presence of UreC and ZapA genes in Proteus mirabilis isolates sourced from Federal Medical Centre and Niger Delta University teaching hospital in Bayelsa State.
\end{abstract}

Materials and methods: A total of one hundred and forty (140) clinical samples were collected from Federal Medical Centre (FMC) Yenagoa and Niger Delta University Teaching Hospital (NDUTH) Okolobiri, Bayelsa State. Of the 140 samples collected, $64(45.7 \%)$ were from males while $76(54.3 \%)$ were from females. The samples were Urine, Sputum, High vaginal swab, Urethral swab, Ear swab and Wound swab. The samples were inoculated in different laboratory media and incubated at $37^{\circ} \mathrm{C}$ for 48 hours. Morphological, cultural, biochemical characteristics and Polymerase Chain Reaction (PCR) technique were noted appropriately. Means and corresponding standard deviations were calculated for continuous data while proportions, along with the $95 \%$ confidence intervals, were calculated for categorical data.

Results: A total of 81 bacterial isolates were obtained from these samples, of which $17(20.9 \%), 22(27.2 \%), 8(10.0 \%), 10(12.3 \%)$ and $24(29.6 \%)$ were Proteus mirabilis, Escherichia coli, Pseudomonas aeruginosa, Klebsiella pneumoniae and Staphylococcus aureus respectively. Fifteen (15) out of the 17(20.9\%) P. mirabilis isolates were subjected to single-plex PCR amplification using specific primers after extraction of bacterial DNA from the samples. Out of the 15 samples, 14(93.3\%) were positive for UreC gene while $15(100 \%)$ were positive to ZapA gene.

Conclusion: The present study revealed that virulent genes-UreC and ZapA are highly present in $P$. mirabilis isolates obtained from clinical specimens from FMC and NDUTH in Bayelsa state, thus making them more pathogenic and resistant to antibiotics curing effect.
Volume 9 Issue I - 202 I

\author{
Alade Tolulope, Itodo Sunday Ewaoche, \\ Arikekpar lbemologi, Ekanem Edmund \\ Department of Medical Laboratory science, Faculty of Basic \\ Medical Sciences, College of Health Sciences, Niger Delta \\ University, Nigeria
}

Correspondence: Itodo Sunday Ewaoche, Department of Medical Laboratory Science, Faculty of Basic Medical Sciences, Niger Delta University, Wilberforce Island, Bayelsa State, Nigeria, Tel +2348069l89852, Email ewieis@gmail.com

Received: May 20, 2020 | Published: February 25, 2021

Keywords: UreC, ZapA, Proteus mirabilis, NDU, Bayelsa State

\section{Introduction}

The persistence of an infection even after supposedly proper treatment could be as a result of wrong diagnosis, medication errors, rational choice of drugs, postulate treatment outcomes, drug interactions, and potential adverse drug reactions, low level of your immunity and resistance of the antimicrobials by the etiologic agents.

If the persistence of the infections is central to the resistance of the antimicrobial agents which is the failure of microorganisms notably bacteria, fungi, parasites viruses to resist the effects of medications that were previously used to treat them and the resistance faced by medications notably antibiotics that had previously treated an infection of bacteria origin termed antibiotic resistance (ABR), then there is a need to look closely at these central resistance genes.

Pathogenic bacteria have worked out many different ways to overcome the host defense system. A number of biological features known as virulence factors are common to many bacterial species, although some of these are characteristic only for certain bacteria. ${ }^{1}$ The genus Proteus is a Gram-negative bacillus that belongs to the Enterobacteriaceae family. Members of the genus Proteus are widespread in the environment and the gastrointestinal tract of human and animals. ${ }^{2}$ Proteus is known as nosocomial, opportunistic pathogen and is more common in community-acquired infections. ${ }^{3}$

Proteus mirabilis is one of the most common causes of UTI in individuals with long-term indwelling catheters, or complicated UTIs, and of bacteremia among the elderly (Liaw et al., 2004). ${ }^{4,5}$ It is a Gram-negative rod shaped bacterium, well-known for its urease production and distinctive ability to differentiate into elongated swarm cells and characteristic bull's-eye pattern of motility on agar plates. It belongs to the class- Gammaproteobacteria, order-Enterobacteriales, family-Enterobacteriaceae, genus-Proteus, and specie- mirabilis. ${ }^{6}$ It is a non-lactose fermenter organism, positive to urease test, citrate utilization test, hydrogen sulphide production test and phenylalanine deaminase test, but negative to indole, and sucrose fermentation tests. $^{7}$ It is an opportunistic bacterial pathogen which under favorable conditions causes many diseases such as UTIs, and especially with complicated UTI. ${ }^{8}$ Usually, they affect the upper part of urinary tract causing infections such as cystitis, urolithiasis (kidney or bladder stones), and acute pyelonephritis and occasional cases of neonates or infants' meningitis, bacteremia, wound infections, septicemia, and rheumatoid arthritis. ${ }^{9}$ P. mirabilis expresses several virulence factors 
involved in uropathogenesis such as adhesions, swarming motility, urease, hemolysin, proteases, and lipopolysaccharide endotoxins. ${ }^{10}$ UreC encodes the large subunit the urea-inducible urease gene cluster (ureRDABCEFG) \} responsible for the production of urease enzyme by P. mirabilis, and it is very highly conserved among all species, so is regarded as a diagnostic feature of $P$. mirabilis. ${ }^{11,12}$ Urease assists $P$. mirabilis to develop bacteriuria, cystitis, as well as kidney, and bladder stones. ${ }^{13}$

ZapA (mirabilysin/serralysin) is a metalloprotease capable of mediating the degradation of numerous host proteins in vitro. ZapA has been considered to have a role as virulence factor for P. mirabilis. However, its role in the pathogenicity of this bacterium is associated with the hydrolysis of IgA, which would destroy an important component of the host defense system of mammalian mucous surfaces. It is possible, however, that the enzyme may be effective for microbial proliferation, destroying other bioactive molecules like defensins, involved in the innate defense, or structural components of the host cells like matrix proteins. ${ }^{14}$

\section{Materials and methods}

\section{Study design}

This was a Cross-sectional study involving the use of quantitative methods for data collection in Yenagoa and Okolobiri, Bayelsa State.

\section{Study area}

This study was carried out in Federal Medical Center (FMC), Yenagoa and Niger Delta University Teaching Hospital (NDUTH), Okolobiri, Bayelsa State. Bayelsa State is a multicultural state in the southern part of Nigeria in the core Niger Delta region. Geographically, Bayelsa State is located within Latitude: $04^{\circ} 15^{\prime}$ North, $05^{\circ} 23^{\prime}$ South and Longitude: $05^{\circ} 22^{\prime}$ West and $06^{\circ} 45^{\prime}$ East. It shares boundaries with Delta State on the North, Rivers State on the East and Atlantic Ocean on the West and South and is populated by different ethnic groups across the country.

\section{Ethical Clearance}

Ethical clearance was obtained from the ethical committee of Niger Delta University Teaching Hospital (NDUTH), Okolobiri and Federal Medical Center (FMC), Yenagoa.

\section{Specimen collection}

A total of one hundred and forty (140) samples were obtained from the Microbiology Department of Niger Delta University Teaching Hospital (NDUTH), Okolobiri and Federal Medical Center (FMC), Yenagoa, Bayelsa State. Sterile swabs sticks and containers (commercially obtained) were used for sample collection. Large mouth sterile containers were used for urine and sputum samples collection; sterile swab sticks moistened with normal saline were used for high vaginal swabs (HVS), urethral swabs, ear swabs and wound swabs samples collection. Culture media used were MacConkey agar (Oxoid), Chocolate agar (Oxoid) and Nutrient ager (oxoid). Swab sticks were dipped into peptone water before $24 \mathrm{hrs}$ of incubation at $37^{\circ} \mathrm{C}$. One (1) $\mathrm{ml}$ of the broth culture was inoculated onto prepared plate of mac Conkey agar, Nutrient agar and chocolate agar. The plates were incubated for 18 hours and the pure cultures of the isolates stored on nutrient agar slant at $4^{\circ} \mathrm{C}$ until needed.

\section{Antibiogram}

This was carried out by agar disc diffusion method using commercially available discs to determine susceptibility pattern of the isolates. The antibiotics used were Tarivid (OFX), Reflacine (PEF), Ciprofloxacin (CPX), Augmentin (AU), Ampicillin (PN), Gentamycin (CN), Streptomycin (S), Ceporex (CEP), Nalidixic acid (NA), Cotrimoxazole (SXT), Amoxicillin (AML), Norfloxacin (NB), Rifampicin (RD), Erythromycin (E), Ampiclox (APX), Levofloxacin (LEV) and Chloramphenicol (CH). Nutrient agar plate was flooded with peptone broth containing the isolates; excess broth on the agar was drained off and the antibiotic disc was then placed on the surface of the agar and incubated at $37^{\circ} \mathrm{C}$ for 24 hours. Sensitivity/ susceptibility to a particular antibiotic was indicated by a clear zone of inhibition around it. The zones of inhibition were measured by the diameter in millimeters ( $\mathrm{mm}$ ) using a meter rule (Gary, 2011).

\section{Molecular analysis}

\section{DNA extraction (Boiling Method)}

An overnight culture of the pure isolate in peptone broth was transferred into a $2 \mathrm{ml}$ Eppendorf tube and was spun at $14000 \mathrm{rpm}$ for 3 minutes in a Denville $260 \mathrm{D}$ brushless micro-centrifuge manufactured by Denville Scientific Incorporated. The supernatant was then discarded and $1000 \mu$ of $0.5 \%$ normal saline was added to the sediment and was vortexed on el tech XH-B vortex. The tube was inserted into a heating block at $95^{\circ} \mathrm{C}$ for 20 minutes, after which it was fast cooled in a freezer for 10minutes. On cooling, the tube was spun again at $14000 \mathrm{rpm}$ for 3 minutes and $500 \mu \mathrm{l}$ of the supernatant (containing the bacterial DNA) was aspirated and dispensed into a $1.5 \mathrm{ml}$ Eppendorf tube and was stored in the freezer at $-2^{\circ} \mathrm{C}$ for preservation and further analysis.

\section{DNA quantification}

Quantification of the extracted bacterial DNA was done using a Nanodrop 1000 spectrophotometer. Two (2) $\mu 1$ of the extracted bacterial DNA was placed on the lower pedestal using an automated micropipette and the higher pedestal was dropped at that same spot. The quantity and purity of the DNA was read off the computer.

\section{Amplification of UreC and ZapA gene}

The PCR mix comprised X2 dream taq master mix (Taq polymerase, dNTPs, $\mathrm{MgCl}$, buffer), the primers (forward and reverse) at a concentration of $0.4 \mu \mathrm{M}$ (supplied by Inqaba Biotech, South Africa), template (the extracted bacterial DNA), and water. Each PCR amplification process was done in 35 cycles and is summarized below (table $1 \& 2$ ).

Table I Programs of PCR thermocycling conditions

\begin{tabular}{lll}
\hline Amplification processes & Ure $\mathrm{C}$ gene & ZapA gene \\
\hline Initial denaturation & $95^{\circ} \mathrm{C}-5$ minutes & $95^{\circ} \mathrm{C}-3$ minutes \\
Final denaturation & $95^{\circ} \mathrm{C}-30$ seconds & $95^{\circ} \mathrm{C}-$ Iminutes \\
Annealing & $54^{\circ} \mathrm{C}-30$ seconds & $60^{\circ} \mathrm{C}-$ Iminutes \\
Initial extension & $72^{\circ} \mathrm{C}-30$ seconds & $72^{\circ} \mathrm{C}-$ Iminutes \\
35 cycles repeated & & \\
Final extension & $72^{\circ} \mathrm{C}-3$ minutes 30 secs & $72^{\circ} \mathrm{C}-5$ minutes \\
Infinity $(\infty)$ allow to cool & $10^{\circ} \mathrm{C}$ forever & $4^{\circ} \mathrm{C}$ forever \\
\hline
\end{tabular}

\section{Agarose gel electrophoresis:}

A $5 \mu 1$ aliquot of each amplicon was resolved on 1.5\% Agarose gel electrophoresis tinted with Ethidium Bromide at $120 \mathrm{~V}$ for 30 minutes and was visualized with an ultraviolet trans-illuminator. The sizes of the DNA were determined using a Quick load 1000bp Molecular DNA ladder. 


\section{Results}

Table 3 shows that majority of the respondents were females 76(54.3). However, comparing the High Vaginal Swab and Urethral Swab, the male respondents recorded more samples.

Table 4 shows that respondents within the ages of 21-30 recorded the highest rate of infection $18(45.0 \%)$, closely followed by the age bracket of $31-40-8(20.0 \%)$ and the lowest among the elderly 51-60$3(7.5 \%)$.

Table 2 The sequence primers of UreC and ZapA genes (Ali and Yousif, 20I5).

\begin{tabular}{llc}
\hline Genes & Primer sequences (5'-3') & Size of base pair \\
\hline \multirow{2}{*}{ UreC } & Forward: GTT ATT CGT GAT GGT ATG GG & 317 \\
& Reverse: GTA AAG GTG GTT ACG CCA GA & \\
\multirow{2}{*}{ ZapA } & Forward:ACC GCA GGA AAA CAT ATA GCC C & 533 \\
& Reverse: GCG ACT ATCTTC CGC ATA ATCA
\end{tabular}

Table 3 Sex of respondents

\begin{tabular}{lccc}
\hline Specimen & Female (\%) & Male (\%) & Total (\%) \\
\hline Urine & $45(62.5)$ & $27(37.5)$ & $72(5 \mathrm{I} .4)$ \\
Sputum & $10(62.5)$ & $6(37.5)$ & $16(1 \mathrm{I} .4)$ \\
High vaginal swab & $14(100)$ & - & $14(10.0)$ \\
Urethral swab & - & $15(100)$ & $15(1 \mathrm{I} .0)$ \\
Ear swab & $3(33.3)$ & $6(66.7)$ & $9(6.4)$ \\
Wound swab & $4(28.6)$ & $10(71.4)$ & $14(10.0)$ \\
Total & $76(54.3)$ & $64(45.7)$ & 140 \\
\hline
\end{tabular}

Table 4 Age Distribution of bacterial isolates-(Males \%)

\begin{tabular}{|c|c|c|c|c|c|c|}
\hline Age Range & P. mirabilis (\%) & E. coli (\%) & P. aeruginosa (\%) & K. pneumonia (\%) & S. aureus (\%) & Total (\%) \\
\hline$<20$ & - & $4(80.0)$ & - & I (20.0) & - & $5(12.5)$ \\
\hline $21-30$ & $5(28.0)$ & $5(28.0)$ & $2(11.1)$ & I (6.0) & $5(28.0)$ & $18(45.0)$ \\
\hline $31-40$ & $2(25.0)$ & - & - & $3(37.5)$ & $3(37.5)$ & $8(20.0)$ \\
\hline $4 I-50$ & I (I7.0) & $\mathrm{I}(\mathrm{I} 7.0)$ & - & I (I7.0) & $3(50.0)$ & $6(15.0)$ \\
\hline $51-60$ & - & - & I (33.3) & - & $2(67.0)$ & $3(7.5)$ \\
\hline Total (\%) & $8(20.0)$ & $10(25.0)$ & $3(7.5)$ & $6(15.0)$ & $13(32.5)$ & 40 \\
\hline
\end{tabular}

Table 5 Age Distribution of bacterial isolates (Female \%)

\begin{tabular}{|c|c|c|c|c|c|c|}
\hline Age Range & P. mirabilis (\%) & E. coli $(\%)$ & P. aeruginosa (\%) & K. pneumonia (\%) & S. aureus (\%) & Total (\%) \\
\hline$<20$ & I (I4.3) & $5(7 I .4)$ & I (I4.3) & - & - & $7(17.1)$ \\
\hline $21-30$ & $4(25.0)$ & $6(37.5)$ & $2(12.5)$ & $2(12.5)$ & $2(12.5)$ & $16(39.0)$ \\
\hline $31-40$ & $3(25.0)$ & - & $2(17.0)$ & I (8.3) & $6(50.5)$ & $12(29.1)$ \\
\hline $4 I-50$ & I (33.3) & - & - & - & $2(67.0)$ & $3(7.3)$ \\
\hline $51-60$ & - & - & - & I (50.0) & I $(50.0)$ & $2(4.9)$ \\
\hline$>60$ & - & I (100) & - & - & - & I (2.4) \\
\hline Total (\%) & $9(22.0)$ & $12(29.3)$ & $5(12.2)$ & $4(10.0)$ & II (27.0) & 41 \\
\hline
\end{tabular}

Citation: Tolulope A, Ewaoche IS, Ibemologi A, et al. UreC and ZapA virulence genes amplification in clinical specimen of Proteus mirabilis in Bayelsa state, Nigeria.J Microbiol Exp. 2021;9(I):I5-20. DOI: 10.15406/jmen.2021.09.00317 
Table 6 Distribution of bacterial isolates by specimen

\begin{tabular}{|c|c|c|c|c|c|c|}
\hline Specimen & P. mirabilis (\%) & E. coli $(\%)$ & P. aeruginosa (\%) & K. pneumonia (\%) & S. aureus (\%) & Total (\%) \\
\hline Urine & $13(2 \mid .3)$ & $18(29.5)$ & $4(6.5)$ & $7(I I .5)$ & $19(31.1)$ & $6 \mathrm{I}(75.3)$ \\
\hline Sputum & I (100) & - & - & - & - & I (I.2) \\
\hline High vaginal swab & I (25.0) & $2(50.0)$ & - & I (25.0) & - & $4(4.9)$ \\
\hline Urethral swab & $2(100)$ & - & - & - & - & $2(2.5)$ \\
\hline Ear swab & - & I (I6.7) & $2(33.3)$ & - & $3(50.0)$ & $6(7.4)$ \\
\hline Wound swab & - & I (I4.3) & $2(28.6)$ & $2(28.6)$ & $2(28.6)$ & $7(8.6)$ \\
\hline Total & 17 (20.9) & $22(27.2)$ & $8(10.0)$ & $10(12.3)$ & $24(29.6)$ & 81 \\
\hline
\end{tabular}

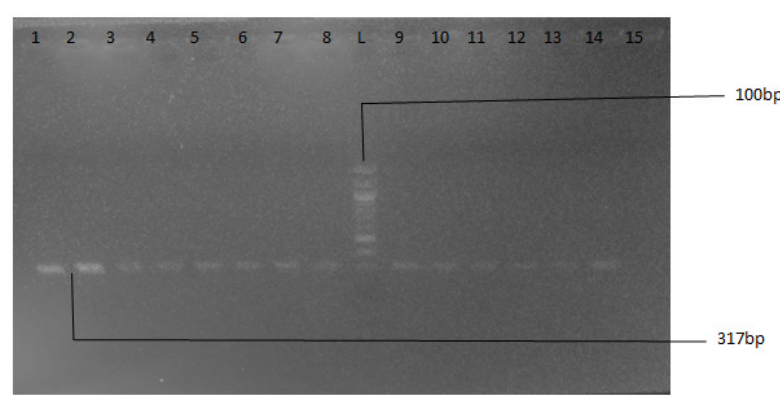

Plate I Agarose Gel Electrophoresis of the UreC gene of some selected bacterial isolates. Lane I-I4 represents the UreC gene bands (3I7bp). Lane L represents the I00bp Molecular ladder.

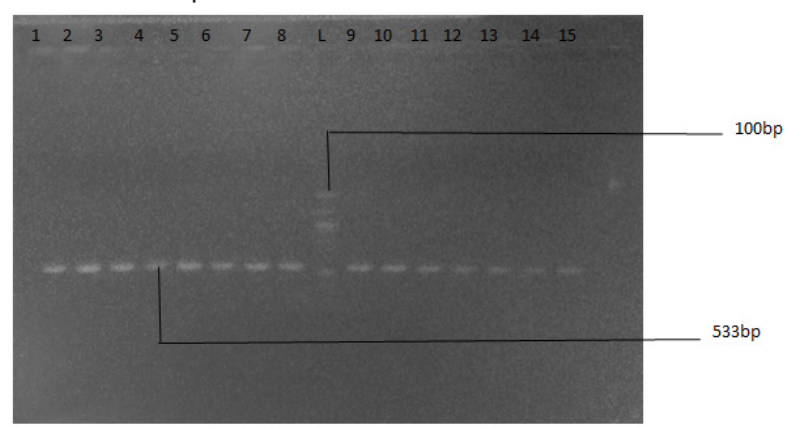

Plate 2 Agarose Gel Electrophoresis showing bands of ZapA gene (533bp). Lane $\mathrm{I}-\mathrm{I} 5$ represents the samples while $L$ represents $100 \mathrm{bp}$ molecular ladder.

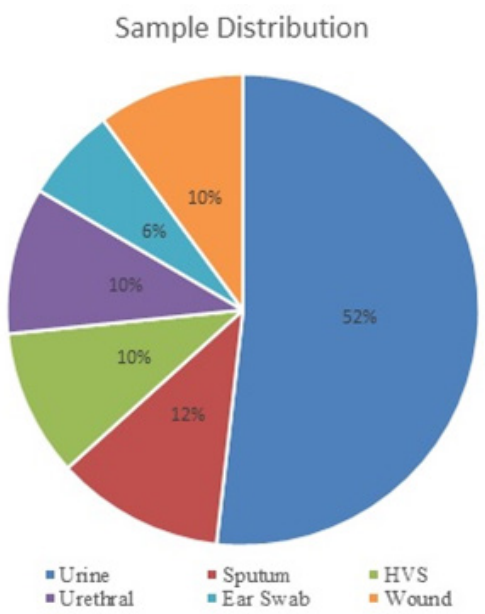

Figure I Pie chart showing the distribution of clinical samples.

\section{Discussion}

P. mirabilis uses various set of virulence factors to access and colonize the host urinary tract, including urease and protease. It accounts for most of the urinary tract infections that occur in hospital settings and for $90 \%$ of Proteus infections. ${ }^{15}$

A sum total of one-hundred and forty (140) samples were collected; 76(54.3\%) were from female patients and 64(45.7\%) were from male patients. Of the $72(51.4 \%)$ urine specimens, $27(37.5 \%)$ were obtained from males while $45(62.5 \%)$ were from females. Of the $16(11.4 \%)$ sputum samples, $10(62.5 \%)$ were obtained from female patients while 6(37.5\%) were from males. A total of 14(10.0\%) High vaginal swabs (HVS) were collected from $14(100 \%)$ female patients. A total of $15(11.0 \%)$ urethral swabs were obtained from $15(100 \%)$ male patients. Of the $9(6.4 \%)$ ear swabs, $6(66.7 \%)$ were from males while $3(33.3 \%)$ were from females. Of the $14(10.0 \%)$ wound swabs, $10(71.4 \%)$ of the samples were obtained from male patients while $4(28.6 \%)$ were from female patients.

In male patients below 21 years of age, 5(12.5\%) isolates were recovered, 4(80\%) of which were E. coli and 1(20\%) was $K$. pneumonia. In males within the age range of 21-30 years, 18(45.0) isolates were recovered; $5(28.0 \%)$ were $E$. coli, $2(11.1 \%)$ were $P$. aeruginosa, $1(6.0 \%)$ was $K$. pneumonia and $5(28.0 \%)$ were $S$. aureus. A total of $8(20.0 \%)$ isolates were recovered from male patients within the age range of $31-40$ years; $2(25.0 \%)$ were $P$. mirabilis, $3(37.5 \%)$ were $K$. pneumonia and $3(37.5 \%)$ were $S$. aureus. In males within the age of $41-50$ years, $6(15.0 \%)$ isolates were recovered, $1(17.0 \%)$ was P. mirabilis, $1(17.0 \%)$ was E. coli, $1(17.0 \%)$ P. aeruginosa and $3(50.0 \%)$ were $S$. aureus. Isolates recovered from male patients within the age range of 51-60 years were $3(7.5 \%)$, of which $1(33.3 \%)$ was $P$. aeruginosa and $2(67.0 \%)$ were $S$. aureus.

For female patients below the age of 21 years old, 7(17.1\%) isolates were recovered; $1(14.3 \%)$ P. mirabilis, $1(14.3 \%) P$. aeruginosa and 5(71.4) E. coli. Within the age range of 21-30 years, $16(39.0 \%)$ isolates were recovered; $4(25.0 \%)$ P. mirabilis, $6(37.5 \%)$ E. coli, $2(12.5 \%)$ P. aeruginosa, 2(12.5\%) K. pneumonia and $2(12.5 \%) S$. aureus. In females within the ages of 31-40 years, the total isolates recovered were $12(29.1 \%)$, of which $2(25.0 \%)$ were P. mirabilis, $2(17.0 \%)$ were $P$. aeruginosa, $1(8.3 \%)$ was $K$. pneumonia and $6(50.5 \%)$ were $S$. aureus. A total of $3(7.3 \%)$ isolates were recovered from females within the age range of $41-50$ years; $1(33.3 \%)$ P. mirabilis and $2(67.0 \%)$ S. aureus. For females within 51-60 years old, 2(4.9\%) isolates were recovered; $1(50.0 \%)$ K. pneumonia and $1(50.0 \%)$ S. aureus. Only $1(2.4 \%)$ isolate was recovered from females above 60 years old and that was $1(100 \%)$ E. coli. In summary, a total of $8(20.0 \%)$ and $9(22.0 \%)$ P. mirabilis were recovered from male and female patients respectively. A total 
of $10(25.0 \%)$ and $12(29.3 \%) E$. coli were from males and females respectively. A total of $3(7.5 \%) P$. aeruginosa were recovered from male patients and $5(12.2 \%)$ were from females. A total of $6(15.0 \%)$ $K$. pneumonia were recovered from males and $4(10.0 \%)$ were from females. A total of $13(32.5 \%) S$. aureus were recovered from male patients and 11(27.0\%) were from females.

A total of eighty-one (81) isolates were recovered. A total of $61(75.3 \%)$ out of 72 urine specimens yielded $13(21.3 \%)$ P. mirabilis, $18(29.5 \%)$ E. coli, $4(6.5 \%)$ P. aeruginosa, $7(11.5 \%)$ K. pneumonia and $19(31.1 \%) S$. aureus. Out of the 16 sputum samples, only $1(1.2 \%)$ yielded $1(100 \%)$ P. mirabilis. A total of $4(4.9 \%)$ HVS out of 14 yielded $1(25.0 \%)$ P. mirabilis, $2(50.0 \%)$ E. coli and $1(25.0 \%)$ $K$. pneumonia. A total of $2(2.5 \%)$ urethral swabs out of 15 yielded 2(100\%) P. mirabilis. A total of 6(7.4\%) ear swabs out of 9 yielded 1(16.7\%) E. coli, 2(33.3\%) P. aeruginosa and 3(50.0\%) S. aureus. A total of 7(8.6\%) wound swabs out of 14 yielded $1(14.3 \%)$ E. coli, $2(28.6 \%) \mathrm{K}$. pneumonia and $2(28.6 \%) \mathrm{S}$. aureus. In summary, a total of $17(20.9 \%)$ P. mirabilis, $22(27.2 \%)$ E. coli, $8(10.0 \%)$ P. aeruginosa, 10(12.3\%) K. pneumonia and 24(29.6\%) were recovered.

Of the 17 isolates of P. mirabilis, 10(58.8), 8(47.1), 13(76.5), 11(64.7), 17(100), 17(100), 17(100), 16(94.0), 16(94.0) and 17(100), were sensitive to Tarivid, Reflacine, Ciprofloxacin, Augmentin, Gentamycin, Streptomycin, Ceporex, Nalidixic acid, Septrin, and Ampicillin respectively. Plates 1 and 2 depict agarose gel electrophoresis of ZapA and UreC gene respectively. Fourteen (14) of 15 samples subjected to PCR amplification were positive for the UreC gene at $317 \mathrm{bp}$ while all the 15 were positive to ZapA gene at $533 \mathrm{bp}$. Lane L is the 1000bp Quick-Molecular ladder. Out of the 140 clinical specimens collected, 76(54.3\%) were from females while $64(45.7 \%)$ were from males. This indicates that the frequency of hospital attendance is higher for females than males. This analysis therefore agrees with Bertakis et al., 2000 whose study showed that females are more likely to attend health clinics and utilizes health care services than the male counterparts.

Individuals within the age range of $21-30$, are prone to any sexually transmitted infections due to their active sexual lifestyle with multi-sex partners as well as physical activities. The present study reveals that the highest number of $P$. mirabilis were isolated in males $5(28.0 \%)$ and females $4(25.0 \%)$ within these age range (21-30years). This is in agreement with the Center for Disease Control and Prevention (CDCP, 2015) ${ }^{16}$ which stated that regardless of race or gender, sexually active adolescents and young adults between 15-30 years are at increased risk for STIs when compared to older adults. It also counters the statement of Cheesbroug, ${ }^{7}$ which states that $P$. mirabilis is a common cause of urinary infection in the elderly and young males and often following catheterization or cystoscopy.

Armbruster et al., ${ }^{10}$ in his study posited that females are mostly affected by urinary tract infections than males. The high incidence of UTIs in females could be as a result of sexual activity, shorter urethra, birth control or menopause. ${ }^{7}$ Our present study was in tandem with their study as the total number of $P$. mirabilis isolated from different clinical specimens were 17 with slightly more isolates from females $9(22.0 \%)$ than males $8(20.0 \%)$.

It has been hypothesized that $P$. mirabilis has access to the bladder by infecting the periurethral area. Apart from these, once an infection is established, the pathogen passes through the urethra via swarming motility to the bladder. P. mirabilis binds to bladder epithelial cells where it eventually colonizes. ${ }^{17}$ In this study, the incidence of $P$. mirabilis in relation to the clinical specimens revealed that the most frequent occurrence was seen in urine $\{13(21.3 \%)\}$ and this coincides with the study of Agbagwa and Ifeanacho (2005) which indicated that pathogens causing urinary tract infections (UTIs) are mostly isolated from urine specimens. As an opportunistic pathogen, it was also isolated from sputum, high vaginal swab (HVS) and urethral swab. The antibiotic susceptibility pattern showed that $P$. mirabilis is susceptible to the Ciprofloxacin, Gentamycin, Streptomycin, Ceporex, Nalidixic acid, Septrin and Ampicillin. This is in agreement with Cheesbrough, ${ }^{7}$ in quote, "antibiotics with activity against $P$. mirabilis include ampicillin, cephalosporins and aminoglycosides". The result was also in agreement with Tsai et al. ${ }^{18}$

The results of the agarose gel electrophoresis revealed 533bp for ZapA gene and $317 \mathrm{bp}$ for UreC gene with complete positive bands which was in accordance with the study carried out by Ali and Yousif 2015. Ure C gene is responsible for the production of urease enzyme which causes the elevation of urine $\mathrm{pH}$, resulting in stone formation and other UTIs. ${ }^{19}$ Dumanski et al., ${ }^{20}$ reported that urease during Proteus UTI is the accumulation of toxic levels of ammonia from urease-mediated hydrolysis of urea that damages tissues including renal epithelia. ZapA is a metalloprotease capable of mediating the degradation of numerous host proteins in vitro. According to Belas et al., ${ }^{21}$ protease enzyme is capable of cleaving IgA, IgG, secretory component and antimicrobial peptides which reduces their antimicrobial activity. ZapA may also contribute to evading the innate immune response during infection of $P$. mirabilis. Therefore, the presence of these genes makes the organism more pathogenic and resistant to antibiotics curing effect.

\section{Conclusion}

With the aid of Polymerase Chain Reaction (PCR) molecular technique, we have been able to detect the high presence of UreC and ZapA virulent genes in Proteus mirabilis isolated from different clinical specimens in our hospitals in Bayelsa state; which makes them more pathogenic and resistant to antibiotics curing effect. Therefore, PCR and other molecular diagnostic methods hold the hope of making rapid diagnosis and directed therapy a reality.

\section{What is known about this topic?}

- Naturally the body flourishes from co-existing with trillion of bacteria, bacteria in turn become defensive by developing resistant genes in form of UreC and ZapA central to assault by chemicals supposedly designed to killed them.

- These resistant genes in Proteus mirabilis are common in the hospital environment and can easily be transmitted.

\section{What this study adds}

- The molecular identification of these two genes associated with $P$. mirabilis was carried out with high through put technology in the South-South region of Nigeria.

- People are now increasingly becoming aware of the resistant genes that can easily be transmitted from $P$. mirabilis in the hospital environments in the South-South region of Nigeria

- The study showed that what keeps us healthy is our immune system, and that proper hygiene and sanitation is very much high yield in living healthy.

\section{Authors' contributions}

Alade Tolutope: Conception and design; Itodo, Sunday Ewaoche: manuscript drafting, revising manuscript for intellectual content and data analysis; Arikekpar Ibemologi: Conception and design; Ekanem Edmund: Data collection and statistical analysis. The authors read and agreed on the final version of the manuscript. 


\section{Acknowledgments}

We wish to wholeheartedly express our profound gratitude to Prof. Tatfeng Y.M for tutoring, professional advice and for availing us the opportunity to make use of his Molecular Laboratory.

\section{Competing interest}

The authors declared no competing interest.

\section{References}

1. Finlay BB, Falkow S. Common Themes in Microbial Pathogenicity. Microbiology Review. 1989;53(2):210-230.

2. Hegazy. Diclofenac Inhibits Virulence of Proteus mirabilis Isolated from Diabetic Foot Ulcer. African Journal of Microbiology Research. 2016;10:733-743.

3. Omoruyia EA, Evangelista M. Proteus mirabilis Septicemia and Meningitis in a Neonate. Journal of Medical Cases. 2014;5(4):245-247.

4. Stickler D, Young R, Jones G, et al. Why are Foley Catheters so Vulnerable to Encrustation and Blockage by Crystalline Bacterial Biofilm? Urological Research. 2003;31(5):306-311.

5. Gaisser S, Hughes C. A Locus Coding for Putative Non-Ribosomal Peptide/Polyketide Synthase Functions is Mutated in a Swarmingdefective Proteus mirabilis strain. Molecular and General Genetics. 1997;253(4):415-427.

6. Adeolu M, Alnajar S, Naushad S, et al. Genome Based Phylogeny and Taxonomy of the 'Enterobacteriales': Proposal for Enterobacterales ord. nov. divided into the families Enterobacteriaceae, Erwiniaceae fam. nov., Pectobacteriaceae fam. Nov, Yersiniaceae fam. Nov., Hafniaceae fam. nov., Morganellaceae fam. nov., and Budviciaceae fam. nov. International Journal of Systematic and Evolutionary Microbiology. 2016;66(12):5575-5599.

7. Cheesbrough M. District Laboratory Practices in Tropical Countries. $2^{\text {nd }}$ ed. Cambridge University Press; 2006. 188-189 p.

8. Al-Duliami AA, Nauman NG, Hasan AS, et al. Virulence Factors of Proteus mirabilis Isolated from Patients with Otitis media in Baquba and its Peripheries. Diyala Journal of Medicine. 2011;1(1):69-75.

9. Hasan AS, Al-Azawi ZH. Virulence Factors of Proteus mirabilis Isolated from Patients with Otitis media in Baquba and its Peripheries. Diyala Journal of Medicine. 2011;1(1):69-75.
10. Armbruster CE, Mobley HL. Merging Mythology and Morphology: The Multifaceted Lifestyle of Proteus mirabilis. National Review Microbiology. 2012;10(11):743-754.

11. Schabereiter-Gurtner C, Maca S, Rollenke S. 16S rRNA-based Identification of Bacteria from Conjunctival swabs by PCR and DGGE fingerprinting. Investigative Ophthalmology and Visual Science, 2001;42(6):1164-1171.

12. Shoket H, Ali S, Gupta RK, et al. Occurrence of Proteus mirabilis Associated with Vegetable Samples in Dehradun, Uttarakhand, India. International Journal of Current Microbiology and Applied Sciences. 2014;3(7):958-961.

13. Limanskii A, Minukhin V, Limanskaia O. Specific Detection of Proteus vulgaris and Proteus mirabilis by the Polymerase Chain Reaction. Journal of Microbiology, Epidemiology and Immununology. 2005;3:3339.

14. Walker KE, Moghaddame-Jafari S, Lockatell CV, et al. ZapA, the IgA Degrading Metalloprotease of Proteus mirabilis, is a Virulence Factor Expressed Specifically in Swarmer Cells. Molecular Microbiology. 1999;32(4):825-836.

15. Gonzales G. Proteus Infections. eMedicine; 2006.

16. Schaffer JN, Pearson M. Proteus mirabilis and Urinary Tract Infection Microbiol Spectr. 2015;3(5):10.1128/microbiolspec.UTI-0017-2013.

17. Coker C, Poore CA, Li X, et al. Pathogenesis of Proteus mirabilis in Urinary Tract Infection. Microbes and Infection. 2000;2(12):1497-1505.

18. Hsih-Yeh Tsai, Yen-Hsu Chen, Hung-Jen Tang, et al. Carbapenems and piperacillin/tazobactam for the treatment of bacteremia caused by extended-spectrum Beta lactamase-producing Proteus mirabilis. Diagnostic microbiology and infectious disease. 2014;80(3):222-226.

19. Mohammed SO, Elshahaby OA, Hafez EE, et al. Characterization and Purification of urease Enzyme from New Proteus mirabilis Strain. $J A d v$ Sci Res. 2014;5(4):8-11.

20. Dumanski AJ, Hedelin H, Edin-Liljegren A, et al. Unique Ability of the Proteus mirabilis Capsule to Enhance Mineral Growth in Infectious Urinary Calculi. Infections and Immunity. 2004;62(7):2998-3003.

21. Belas R, Manos J, Suvanasuthi R. Proteus mirabilis ZapAmetalloprotease Degrades a Broad Spectrum of Substrates, including Antimicrobial peptides. Infections and Immunity. 2004;72(9):5159-5167. 